\title{
TRUNK MUSCLES' RESPONSE TO CORE STABILTY EXERCISES IN PATIENTS WITH CHRONIC LOW BACK PAIN: A RANDOMIZED CONTROLLED TRIAL
}

Sobhy M Aly*.

*Department of Biomechanics, Faculty of Physical Therapy, Cairo University, Cairo, Egypt.

\section{ABSTRACT}

Background: Core stability training has been widely advocated for management of patients with chronic low back pain to minimize attacks and as a preventive measure; however specific effects of this type of training are not fully investigated.

Purpose: The purpose of this study was to investigate trunk muscles' response to core stability exercises in patients with chronic low back pain.

Materials and Methods: Thirty male patients who had nonspecific chronic low back pain were randomly assigned to either core stability training or dynamic strength training for 8 weeks. Peak torque of trunk flexors and extensors were evaluated using the Biodex Isokinetic System; and endurance time for flexors, extensors, and lateral trunk musculatures were evaluated through M cGill's core endurance tests.

Results: There was a significant increase in trunk muscles' peak torque and endurance time in core stability exercises group compared with lumbar dynamic strength exercises group post treatment. Both groups showed improvement in trunk flexors and extensors strength; however, core stability group improved endurance time for trunk flexors, extensors, and lateral muscles, dynamic strength group improved endurance time of flexors and extensors but not of the lateral muscles.

Conclusion: Core stability exercises effectively increase trunk muscles' strength and endurance. The core stabilization exercises are more effective in improving strength and endurance of trunk muscles than the dynamic strengthening exercises in the patients with chronic low back pain.

KEY WORDS: Core stability, low back pain, endurance, Trunk muscles.

Address for correspondence: Dr. Sobhy M Aly, PhD., Department of Biomechanics, Faculty of Physical Therapy, Cairo University, Cairo, Egypt. E-mail: drsobhymahmoud@gmail.com

\begin{tabular}{|c|c|c|}
\hline \multicolumn{3}{|c|}{ Access this Article online } \\
\hline \multirow{2}{*}{$\begin{array}{l}\text { Quick Response code } \\
\text { Dol: } 10.16965 / \text { ijpr.2016.201 }\end{array}$} & \multicolumn{2}{|c|}{$\begin{array}{c}\text { International Journal of Physiotherapy and Research } \\
\text { ISSN } 2321-1822 \\
\text { www.ijmhr.org/ijpr.html }\end{array}$} \\
\hline & $\begin{array}{l}\text { Received: 06-12-2016 } \\
\text { Peer Review: 07-12-2016 } \\
\text { Revised: None }\end{array}$ & $\begin{array}{l}\text { Accepted: 04-01-2017 } \\
\text { Published (0): 11-02-2017 } \\
\text { Published (P): 11-02-2017 }\end{array}$ \\
\hline
\end{tabular}

\section{INTRODUCTION}

Low back pain (LBP) that persists longer than 12 weeks is defined as chronic LBP (CLBP) [1]. CLBP is the most frequent complaint of orthopedic diseases in Europe and United States [2], and one of the primary cause of work absence and disability $[3,4]$. The specific cause of CLBP is not identified and not clear in about $85 \%$ of patients, this type of pain can be termed nonspecific LBP. Nonspecific LBP is closely related to altered lumbar stability [5].

Recent studies on treatments for CLBP have been focused on improving trunk stability to minimize recurrent episodes and maximize prevention [6]. Stabilization exercises have been designed to enhance the neuromuscular control system and correct the dysfunction [7].

Besides prevention of LBP, the strengthening of the stabilizing muscles of the trunk is considered of great importance to daily activities and 
sports [8]. Core stability training is a form of training that challenges the stability of the spine while training muscle activity patterns and postures that ensure sufficient stability without unnecessarily overloading tissue $[9,10]$. Trunk stabilization exercises are based on co-contraction of the abdominal and multifidus muscles, and they are also performed in a variety of body positions [11]. Core stability training is directed at training the deep trunk muscles [12].

The lumbar stabilizing muscles are divided into local and global muscles, based on their role in stabilizing the trunk [13]. The multifidus, transversus abdominis, internal oblique, medial fibers of external oblique, the quadratus lumborum, diaphragm, and pelvic floor muscles constitute the local stabilizing system $[14,15]$, whereas rectus abdominis, lateral fibers of the external oblique, psoas major, and the erector spinae constitute the global stabilizing muscles [16]. Lumbar stability is primarily managed by the local muscles, whereas the global muscles, which are generally multisegmental, are the primary producers of movement. Although global musculature, in combination with local musculature, play an important role in stability, global muscles contribute primarily compressive forces to stability, and are limited in their ability to control segmental shear forces [17].

Core stabilization exercises have been recommended in rehabilitation programs for low back and lower extremity pathology [18]. Compared with typical resistance training, core strength training is easier for CLBP patients to learn, although it is more challenging [19]. However, the effectiveness of core stabilization exercises remains uncertain $[20,21]$, and the effectiveness of core stability exercises in the management of CLBP is ambiguous [21]. Outcomes of stabilization exercises as an intervention for CLBP often based the findings on measures mainly associated with either pain, disability, and balance [11,21-23]. The tools used were the visual analog scale or McGill pain questionnaire and questionnaires such as the Oswestry Disability Index or Roland M orris Disability Questionnaire [24].

The overall conclusion from previous studies suggested that lumbar stabilization exercises are effective in treating CLBP, but it does not appear to be more effective than other exercise programs. There is a lack of high quality evidence available to support or refuse the use of core stabilization programs [25]. There is still insufficient evidence that reflects changes in muscle strength and endurance in response to core stability exercises. Therefore, this study aimed to quantify the effect of core stability exercises on trunk muscle strength and endurance in subjects with nonspecific CLBP.

\section{MATERIALS AND METHODS}

Design: A randomized controlled trial was conducted to evaluate the effect of core stability exercises on trunk muscles' strength and endurance versus traditional dynamic strength exercises.

Subjects: Thirty male patients who had nonspecific LBP for 3 months or longer were recruited from the faculty outpatient clinic to participate in this study. Patients were included if they having recurrent episodes of nonspecific LBP without any relevant ongoing pathologies such as disc prolapse, spondylolisthesis, osteoporosis, or infection. Age, body mass, and height ranged from $25-45$ years, $65-85 \mathrm{~kg}$, and $160-178 \mathrm{~cm}$ respectively. Subjects were excluded if they had degenerative conditions affecting the spine, underlying neurological conditions, previous abdominal surgery, a history of heart disease, any contraindication to exercise, trunk muscles' (abdominals and back) strength less than grade three as assessed by manual muscle test, and flexibility of the lower back muscles less than $3 \mathrm{~cm}$ as assessed by modified Schober test. They underwent a history-taking interview and a physical examination by an orthopedic surgeon who was unaware of the treatment procedure. Each participant was informed of the benefits and risks of the study and then signed an informed consent form in accordance with the guidelines of the university's Institutional Review Board and approved for use of human subjects.

Randomization: The participants were randomly allocated to either core stability group $(n=15)$ or dynamic strength group $(n=15)$. The randomization was done by a colleague independent and blind to the study using concealed envelopes within which the group description 
was randomly placed within them.

Instrumentation: Biodex System 4 Multijoint Testing and Rehabilitation isokinetic dynamometer (Biodex M edical System, Shirley, NY, USA) was used for assessing the trunk flexors' and extensors' peak torque through a predetermined range of motion (ROM) at pre and post treatment. Previous studies have demonstrated the reliability and validity of isokinetic devices for measuring muscle strength in adults [26].

\section{Procedure:}

\section{Measurement of trunk muscles' strength:}

Setup and positioning: For testing trunk flexors and extensors, trunk seated compressed protocol was used, isolating trunk movement with no pelvic and hip muscles sharing. The participants were tested while sitting on the adjustable Biodex Isokinetic Dynamometer System chair. The pelvis and thighs were stabilized by straps. Two curved anterior leg pads were secured to adjust the knee block position. A lumbar support pad was located against the lower lumbar spine [27]. The two anterior force application straps were aligned vertically and then connected to another horizontal strap, which was aligned with the second intercostal cartilage on the anterior chest wall when measuring the flexion torque. The posterior force application padded roller bar was placed on the posterior trunk just distal to the spine of the scapula when measuring the extension torque. The participant sat erect with the head being stabilized neutrally against an adjustable head seat. The participant was instructed to maintain crossed forearms position on the anterior chest wall to avoid any jerky movement from the arms. The axis of the dynamometer arm was aligned at the intersection point of the mid-axillary line and the disc space between the $5^{\text {th }}$ lumbar and $1^{\text {st }}$ sacral vertebrae (L5/S1) [28]. The tested trunk ROM were set at $50^{\circ}$ flexion and $20^{\circ}$ extension; thus, the isokinetic testing range were conducted at a total $70^{\circ}$. The position was confirmed with a protractor situated at the side of the testing chair.

Measurements of peak torque: The isokinetic peak torque of trunk flexors and extensors was evaluated in a concentric mode of muscle contraction at angular velocity $60 \% \mathrm{sec}$ throughout a $70^{\circ}$ ROM. This velocity is the most representative of muscle strength according to force velocity relationship $[29,30]$. Each participant performed one practice session of three sub-maximal trunk flexion and extension repetitions prior to actual measurement to get accommodated with the Biodex speed and ROM. M easurements were conducted through three practice sessions. Testing session involved performing five consecutive trunk flexion/ extension repetitions at the available trunk ROM. The participant was instructed to push and pull as hard and as fast as possible. Verbal encouragement was given during the testing procedure to maximize the participant's voluntary effort. The mean trunk flexors' and extensors' peak torques for the three practice sessions were measured.

\section{Measurement of trunk muscles' endurance:}

McGill's core endurance tests [31], comprised of the trunk flexors' test, extensors' test, and lateral trunk muscles' test, are often used to assess trunk muscles' endurance $[32,33]$. The core endurance tests appeared to be reliable and valid measures in LBP with reported high intra-rater and inter-rater reliability [34,35]. Typically, these tests require minimal, inexpensive equipment, and are safe and simple to employ in clinical environments where performance is evaluated by recording the maximum time a person can maintain the test position. A stopwatch was used to record time. Each test was performed three times and the average time were recorded.

\section{Trunk flexors' endurance test measurements:}

The starting position for the trunk flexors' endurance test involved positioning subjects on a plinth with their back resting against a wedge that maintained $60^{\circ}$ flexion from the horizontal. Knees were flexed to $90^{\circ}$ and the feet were stabilized by the examiner. Participants crossed their arms across the chest, placing their hands on opposite shoulders, in a manner comfortable to them. Participants were asked to maintain their body position as long as possible after the wedge was moved back $10 \mathrm{~cm}$. Time was measured from the instant the wedge was moved back until the participant visually reestablished contact with the wedge [31]. 
Trunk extensors' endurance test measurements: For trunk extensors testing, participants were instructed to lie prone. The lower body was fixed to the table surface via straps at the ankles, knees, and hips. The upper body (from just above the level of the anterior superior iliac crest) was off the surface of the plinth. Participants held their upper body off the end of the table by pushing with their extended arms on a chair directly below them. Participants were instructed to maintain the horizontal position as long as possible once testing commenced. At the initiation of the test, the upper limbs were lifted off the chair and crossed over the chest with the hands resting on the opposite shoulders [31].

Lateral trunk musculature endurance measurements: Participants laid on their side with their legs extended, resting on their forearm with the elbow flexed to $90^{\circ}$. Subjects were instructed to lift the hip off the bed and maintain a straight line with the whole body throughout the test. Participants were instructed to maintain the position for as long as possible. This side bridge test optimally challenge quadratus lumborum and the muscles of the anterolateral trunk wall [31].

Treatment: The core stability group performed the beginners' core stability program and the dynamic strength group performed conventional dynamic lumbar strength exercises. Common components of the two programs included a warm-up period. The warm-up exercise involved a "Cat-Camel" motion of the spine (spine flexion-extension cycles) and stretching exercises for calf, hamstring, quadriceps and lower back. The "Cat-Camel" motion was done to reduce spine viscosity (internal resistance and friction) and free the nerve roots as they exit at their respective lumbar levels. The "Cat-Camel" motion was intended as a motion exercise, not a stretch, so the emphasis was on motion rather than pushing at the end ranges of extension and flexion. Five to eight cycles were reported to be sufficient for reducing most viscous-frictional stresses [36].

\section{Core stability exercises:}

The core stability group performed the beginners' core stability program described in table 1. McGill [36] proposed a rehabilitation strategy that incorporates all the core muscles, supported by an in-depth biomechanical rationale for this strategy. This strategy described the "big 3" exercise program to enhance core muscular performance: the curl-up, the side bridge, and the bird dog. The curl up is central to flexion, the side bridge is central to the frontal plane, and the bird dog is central for extensors. The program consisted of three phases, with first phase lasting for two consecutive weeks, second phase lasting for three consecutive weeks, and the last phase lasts for three consecutive weeks. It was conducted three times per week for eight weeks. The program was performed once, twice, and three times per day in the first, second, and third phases respectively. The participant was asked to perform 10 repetitions for each exercise at each session. It is recommended that the isometric holds be held no longer than 7-8 sec because there is a rapid loss of the available oxygen in the torso muscles contracting after these limits. Short relaxation of the muscles restores oxygen [36]. The participant was instructed not to do the core stability exercises in the first hour of awakening because of the increased hydrostatic pressure in the intervertebral discs during this time.

\section{Lumbar dynamic strengthening exercises:}

Dynamic strength group performed conventional lumbar dynamic strengthening exercises described in table 2 . The target muscles for lumbar dynamic strengthening exercises are rectus abdominis, erector spinae, and hip muscles. The exercises were traditional curl up (sit-ups)- knee to chest- bridging- prone on elbows- prone on hands- hip extension - trunk extension.

Exercises were conducted three times per week for eight weeks. The patients performed an average of three series of 10 repetitions of each exercise once daily. Increases in the number of exercises performed in each session (or load progression) occurred according to individual tolerance. For all exercises, the final static position was held for $8 \mathrm{sec}$. There was a pause of $3 \mathrm{sec}$ between repetitions and a $60 \mathrm{sec}$ rest between each exercise.

Statistical analysis: The mean and standard deviation were calculated for all the variables using standard statistical procedures. The Shapiro-Wilks test was used to test the normal 
distribution of data. Unpaired t test was conducted for comparison of subject characteristics between both groups. Two Mixed MANOVA was conducted for comparing trunk flexors' and extensors' peak torque and endurance measurements between pre and post treatment in each group and between groups. The Bonferroni test was conducted as post-hoc tests. The level of significance for all statistical tests was set at $p<0.05$. All statistical analysis was conducted through the statistical package for social sciences (SPSS) version 19 for windows (IBM SPSS, Chicago, IL, USA).

\section{RESULT}

Testing the normal distribution of data: Shapiro-Wilks test was conducted to test the normal distribution of data for each dependent variable. The results revealed no significant deviation from the normal distribution for all variables in both groups ( $p>0.05)$.

Subject characteristics: Table 3, showed the mean \pm SD age, body mass, height, and BM I of core stability and dynamic strength groups. There was no significant difference in the subject characteristics between both groups ( $p>0.05$ ).

\section{Effect of treatment on trunk extensors' and} flexors' peak torque: There was no significant difference between core stability and dynamic strength groups in peak torque of trunk extensors and flexors pre-treatment ( $p>0.05)$. Comparison between groups post treatment revealed a significant increase in trunk extensors' and flexors' peak torque of core stability group compared with dynamic strength group $(p<0.05)$. (Table 4).

There was a significant increase in peak torque of trunk extensors and flexors post treatment compared with pre treatment in both groups ( $p=0.0001$ ) (Table 4).

Effect of treatment on trunk muscles' endurance time: There was no significant difference between core stability and dynamic strength groups in trunk muscles' endurance pre-treatment ( $p>0.05)$. Comparison between groups post treatment revealed a significant increase in trunk extensors', flexors', right and left lateral trunk muscles' endurance time of core stability group compared with dynamic strength group ( $p<0.001$ ) (Table 4).

There was a significant increase in trunk extensors', flexors', right and left trunk muscles' endurance time in core stability group post treatment compared with pre treatment $(p<0.0001)$, while in dynamic strength group there was a significant increase in trunk extensors' and flexors' endurance time post treatment compared with pre treatment ( $p<0.001$ ), and non significant changes in right, and left lateral trunk muscles' endurance time ( $p>0.05)$ (Table 4).

Table 1:Prescriptions of the beginners' core stability program.

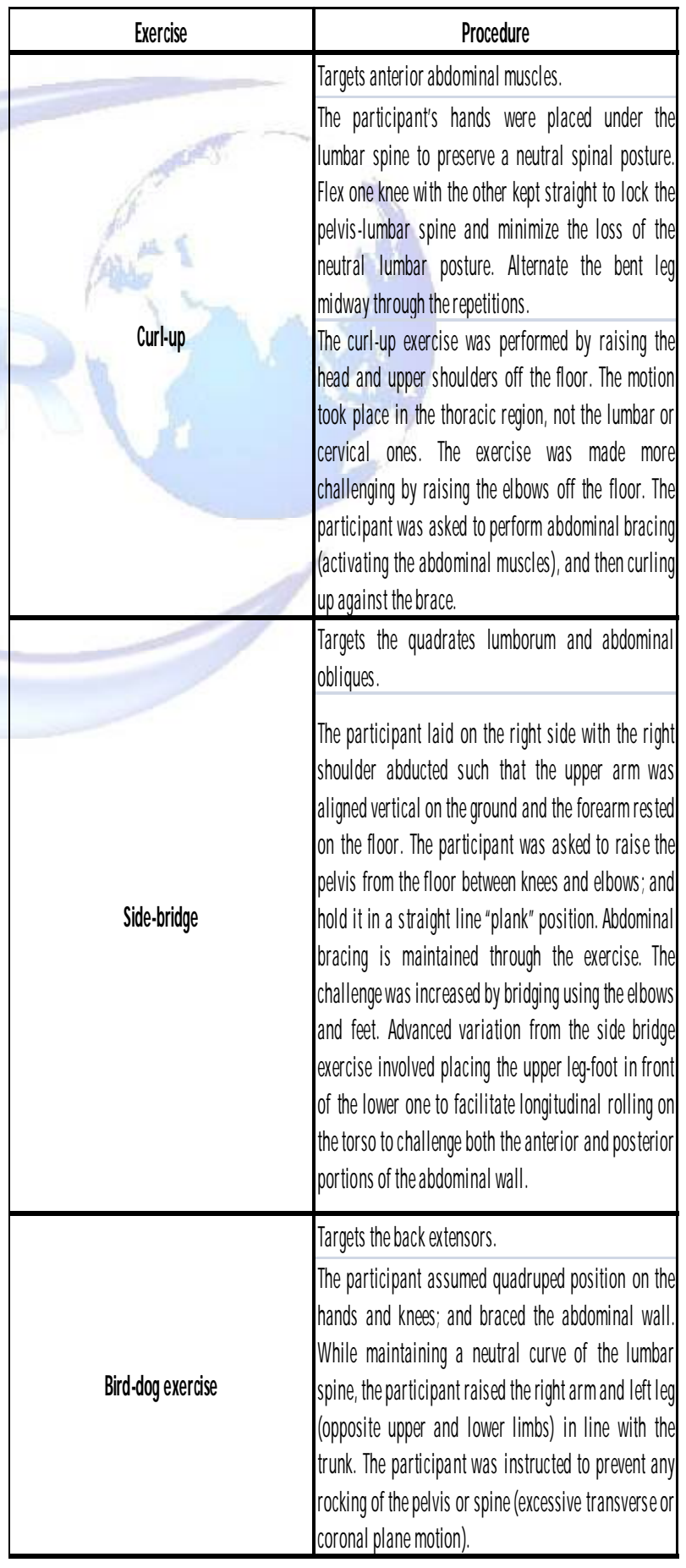




\begin{tabular}{|c|c|c|c|c|c|}
\hline \multicolumn{2}{|l|}{ Exercise } & \multicolumn{4}{|c|}{ Procedure } \\
\hline \multicolumn{2}{|c|}{$\begin{array}{l}\text { The traditional curl-up } \\
\text { (sit-ups) }\end{array}$} & \multicolumn{4}{|c|}{$\begin{array}{l}\text { The participant lies supine with hands beside the body } \\
\text { and legs bent at } 90^{\circ} \text { with feet flat on the floor. The } \\
\text { participants then raised their trunk until their elbows } \\
\text { touched their knees. As a progression, the hands } \\
\text { placed behind the head and shoulder width apart. } \\
\text { Subjects were instructed to exhale as they came up and } \\
\text { inhale during a controlled lowering of the body to the } \\
\text { starting position. }\end{array}$} \\
\hline Knee to chest & & \multicolumn{4}{|c|}{$\begin{array}{l}\text { The participant lies supine with knees bent and feet flat } \\
\text { on the floor. Bring one knee to chest, keeping the other } \\
\text { foot flat on the floor. Keep the lower back pressed to } \\
\text { the floor. Relax and lower the knee to the starting } \\
\text { position then repeat with the other leg. }\end{array}$} \\
\hline Bridging exercis & \multicolumn{5}{|c|}{$\begin{array}{l}\text { The participant lies on back with hips and knees bent } \\
90^{\circ} \text { with feet flat on floor and arms across chest; draws } \\
\text { in abdominal muscles and maintains contraction } \\
\text { through exercise; slowly raise the pelvis off the mat by } \\
\text { using glutes and hamstrings until the trunk is in line } \\
\text { with thighs. }\end{array}$} \\
\hline n elbow & \multicolumn{5}{|c|}{$\begin{array}{l}\text { The participant lies prone on an exercise mat. Place } \\
\text { hands on either side of the head and forehead on the } \\
\text { floor then rises onto elbows and place forearms flat on } \\
\text { the floor. }\end{array}$} \\
\hline Prone on hand & \multicolumn{5}{|c|}{$\begin{array}{l}\text { The participant lies prone and place hands beneath } \\
\text { shoulders and, keeping hips on the floor, raise chest } \\
\text { off the mat by pressing with arms. Gradually increase } \\
\text { range of movement as the set progress. }\end{array}$} \\
\hline Hip extension & \multicolumn{5}{|c|}{$\begin{array}{l}\text { The participant lies prone and raises the thigh } \\
\text { upwards with the knee straight throughout. Slowly } \\
\text { lower the leg back down and then repeats with the } \\
\text { other leg. This exercise intended to strengthen the } \\
\text { hamstrings and gluteus maximus muscles. }\end{array}$} \\
\hline Trunk extension & \multicolumn{5}{|c|}{$\begin{array}{l}\text { From prone position, the participant lifts head and } \\
\text { shoulders upwards, bring shoulder blades together } \\
\text { gently; hold then slowly lowers trunk back to the } \\
\text { starting position and relax completely. As a } \\
\text { progression, arms can be moved outstretched in front } \\
\text { of head, abducted, crossed over back, or crossed over } \\
\text { head. This exercise intended to strengthen back } \\
\text { extensors. }\end{array}$} \\
\hline & \multicolumn{3}{|c|}{$\overline{\mathrm{x}} \pm \mathrm{SD}$} & & \\
\hline & & ore stability & Dynamic strength & $t$ - value & p-value \\
\hline Age (years) & & $38.2 \pm 6.02$ & $36.86 \pm 5.12$ & 0.65 & 0.51 \\
\hline Body mass (kg) & & $76.66 \pm 6$ & $75 \pm 4.86$ & 0.83 & 0.41 \\
\hline Height $(\mathrm{cm})$ & & $170 \pm 6.41$ & $168.8 \pm 5.25$ & 0.56 & 0.58 \\
\hline BMI $\left(\mathbf{k g} / \mathrm{m}^{2}\right)$ & & $6.55 \pm 2.05$ & $26.35 \pm 1.88$ & 0.28 & 0.77 \\
\hline
\end{tabular}

Table 3: Mean age, body mass, height, and BMI of core stability and dynamic strength groups.

Table 2: Prescriptions of the lumbar dynamic strengthening exercises program.

Table 4: Mean trunk muscles' peak torque and endurance time pre and post treatment of core stability and dynamic strength groups.

\begin{tabular}{|c|c|c|c|c|c|c|c|c|}
\hline & \multicolumn{2}{|c|}{ Core stability } & & \multicolumn{2}{|c|}{ Dynamic strength } & & \multicolumn{2}{|c|}{ Between groups } \\
\hline & Pre & Post & & Pre & Post & & Pre & Post \\
\hline & $\overline{\mathrm{x}} \pm \mathrm{SD}$ & $\overline{\mathrm{x}} \pm \mathrm{SD}$ & $p$ value & $\overline{\mathrm{x}} \pm \mathrm{SD}$ & $\overline{\mathrm{x}} \pm \mathrm{SD}$ & $p$ value & pvalue & $p$ value \\
\hline \multicolumn{9}{|l|}{ Peak torque (Nm) } \\
\hline Extensors & $64.77 \pm 12.74$ & $82.4 \pm 10.86$ & $0.0001^{*}$ & $62.58 \pm 9.43$ & $74.84 \pm 8.09$ & $0.0001 *$ & 0.59 & $0.039 *$ \\
\hline Flexors & $48.13+10.54$ & $63.77 \pm 8.15$ & $0.0001 *$ & $49.61 \pm 7.1$ & $57.79 \pm 6.49$ & $0.0001 *$ & 0.65 & $0.035 *$ \\
\hline \multicolumn{9}{|l|}{ Endurance time (sec) } \\
\hline Extensors & $33.4 \pm 4.57$ & $45.2 \pm 6.74$ & $0.0001 *$ & $31.2 \pm 3.64$ & $37.46 \pm 3.68$ & $0.0001 *$ & 0.15 & $0.001 *$ \\
\hline Flexors & $66.13 \pm 7.48$ & $80.8 \pm 8.29$ & $0.0001^{*}$ & $65.53 \pm 5.74$ & $70.53 \pm 5.59$ & $0.0001 *$ & 0.8 & $0.0001 *$ \\
\hline Rt lateral muscles & $43.73 \pm 5.57$ & $58.66 \pm 9.13$ & $0.0001 *$ & $41.4 \pm 6.53$ & $42.46 \pm 5.46$ & 0.41 & 0.3 & $0.0001^{*}$ \\
\hline Lt lateral muscles & $45.6 \pm 5.31$ & $61.66 \pm 5.83$ & $0.0001^{*}$ & $43.33 \pm 3.9$ & $44.8 \pm 4.27$ & 0.16 & 0.19 & $0.0001 *$ \\
\hline
\end{tabular}




\section{DISCUSSION}

Exercise programs that aim to improve the stability of the lumbar spine are widely utilized in the management of patients with CLBP. These programs target a variety of trunk muscles and aim to optimize the control of segmental motion, spinal stability, spinal stiffness, spinal orientation, or a combination of these characteristics [37]. Specific effects of core stability exercises on muscle performance in patients with CLBP are not adequately determined, so the purpose of this study was to investigate changes in trunk muscles' strength and endurance in response to core stability exercises against traditional lumbar dynamic strength exercises in patients with nonspecific CLBP.

Results of this study revealed a significant increase in trunk muscles' peak torque and endurance time in core stability exercises group compared with lumbar dynamic strength exercises group post treatment. Both groups showed improvement in trunk flexors and extensors strength; however, core stability group improved endurance time for trunk flexors', extensors', and lateral muscles' on both sides, dynamic strength group improved endurance time of flexors' and extensors' but not of the lateral muscles'.

Improvement in trunk muscles' peak torque in core stability exercises and dynamic strength exercises may be attributed to increase in cross sectional area of muscles in response to overload. Increase in the cross-sectional area of the lumbar multifidus as a direct result of core stability exercises can be demonstrated within 6 weeks [37]. Core stabilization exercises with the abdominal drawing in maneuver technique has been found to primarily activate the deep abdominal muscles with minimal activity of the superficial muscles [38]. Core stability exercises focus on the lumbar multifidus and transversus abdominis muscles. M ore repetitions of less demanding exercises will assist in the enhancement of endurance and strength [36]. Core stability exercises provide significant activation of transversus abdominis when compared to traditional strength exercises [23].

Danneels et al. [17] investigated the effect of different training schedules on the cross- sectional area of the paravertebral muscles. The cross-sectional area of the paravertebral muscles was found to increase in stabilization training combined with dynamic resistance training group and in stabilization training combined with dynamic-static resistance training group. Stabilization exercises and lumbar resistance training seem to be necessary to restore the size of the paravertebral muscles. They reported that no systematic differences in hypertrophy between dynamic and dynamic-static strengthening training modes were found.

Enhancing core muscle strength is critical in patients with CLBP. People with CLBP have muscle atrophy, especially of the lumbar deep muscles $[39,40]$. Limitation of movement due to pain causes morphological changes in the lumbar muscles that induce decreased muscle strength and endurance. Decreased muscle strength and endurance negatively affect lumbar stability and eventually cause functional limitations [41]. In CLBP the cross-sectional area of multifidus measured with CT is reduced [17]. Furthermore, intramuscular fat in multifidus has been shown to be increased in CLBP $[42,43]$. Increased intramuscular fat is more in deep multifidus fibers [43].

Improvement of endurance time for trunk flexors, extensors, and lateral muscles in core stability group compared to dynamic strength exercises can be attributed to the strategy used in core stability exercises. Core stability exercises provide low load isometric contraction through restricted range of motion [44]. Deep portion of multifidus has a greater percentage of type I (slow twitch) muscle fibers than superficial multifidi and the erector spinae $[45,46]$. Low load isometric contraction provides tonic activation of deep multifidus and other trunk muscles $[46,47]$. Lateral muscles endurance time improved in core stability group only as M cGill rehabilitation strategy incorporates all the core muscles and enhances the muscular endurance capacity of all muscles, not just the transversus abdominis and the multifidi, thus provides stability to the lumbar spine [36].

Because only a minimal level of trunk muscle contraction appears necessary to stabilize the spine, the strength of these muscles appears 
less important than the endurance capabilities of the muscular stabilizing system [6]. Spinal extensors' endurance has been shown to be correlated with decreases in injury risk for the low back [48]. Poor trunk muscular endurance as well as poor flexors'/extensors' endurance ratios hve also been correlated with a history of low back injury [49].

The findings of this study come in agreements with that of Moon et al. [50]. They concluded that both lumbar stabilization and dynamic strengthening exercise strengthened the lumbar extensors and reduced LBP. However, the lumbar stabilization exercise was more effective in lumbar extensor strengthening and functional improvement in patients with nonspecific CLBP. In the same context, Ebrahimi et al. [51] found that core stabilization exercises were more effective than conventional strength exercises in improving LBP, abdominal and back muscle endurance in patients with CLBP caused by disc herniation. Also, Yilmaz et al. [52] investigated the efficacy of lumbar stabilization exercises on trunk muscle strength and flexibility in patients with microdiscectomy. They concluded that lumbar stabilization exercises are an efficient and useful technique in improving functional parameters and strengthening trunk, abdominal and low back muscles.

Also, the findings of this study are consistent with finding of studies investigated the effect of core stability exercises in healthy population. Kumar et al. [53] found that core stability exercise program can be helpful to improve the core strength and physical fitness among school aged participant over a 12 weeks' period compared with control group. Abdallah and Beltagi [54] reported a significant effect of the beginner's core stability exercises on trunk flexors' and extensors' peak torques. Also, Lehman [6] reported that core stability exercises had the ability to adequately strengthen all trunk muscles responsible for maintaining a strong and stable spine without exceeding cautious injury thresholds for compressive and shear loading.

On the other hand, this study disagrees with the findings of Arokoski et al. [47] who found that a core stabilization program, incorporating trunk strengthening exercise in multiple positions did not alter trunk force output or core muscle activation patterns; however, the study examined a very small sample of subjects. A randomized controlled trial by Ferreira et al. [22] compared general exercises and lumbar stabilization exercises in patients with CLBP. The lumbar stabilization exercises groups showed marginally better outcomes than the general exercise group after 8 weeks in VAS and score of the Roland M orris Disability Questionnaire, but there was no significant difference between the two groups. However, the study enrolled a mixed group of subjects (including patients with disc lesions, osteoarthritis, and leg pain), which makes comparison difficult.

Curl up, bird dog, and side bridge had the ability to adequately activate all trunk muscles responsible for maintaining a strong and stable spine without exceeding cautious injury thresholds for compressive and shear loading $[6,55]$. In contrast to lumbar extensors' strengthening exercises, core stability exercises require no special equipment, and patients can independently practice core strength training at home, which is essential because home-based exercise programs can yield additional benefits for motivated patients. Furthermore, several studies have shown that typical resistance training can easily injure CLBP patients [19,56]. M any commonly prescribed trunk muscle exercises for rehabilitation and performance may predispose one to injury due to the high compressive and shear loads imparted on the lumbar spine caused by excessive muscular co-contraction and extreme ranges of motion [57].

\section{CONCLUSION}

Core stability exercises effectively increase trunk muscles' strength and endurance. The core stabilization exercises were more effective in improving strength and endurance than the dynamic strengthening exercise program in the patients with CLBP. Core stability exercises should be an integral component of treatment protocol for patients with LBP.

\section{ACKNOWLEDGEM ENTS}

The author express deep thanks to all participants for their collaboration in this study.

\section{Conflicts of interest: None}




\section{REFERENCES}

[1]. Van Tulder M, Koes B. Chronic low back pain. In Evidence-based chronic pain management. Stannard CF, Kalso E, Ballantyne J, eds. UK: WileyBlackwell/BMJ; 2010.

[2]. Rozenberg S. Chronic low back pain: definition and treatment. Rev Prat 2008;58(3):265-272.

[3]. Peng HY, Lin TB. Spinal pelvic-urethra reflex potentiation. Biomedicine 2012;2(2):64-67.

[4]. Magni G, Caldieron C, Rigatti-Luchini S, M erskey H. Chronic musculoskeletal pain and depressive symptoms in the general population. An analysis of the 1st National Health and Nutrition Examination Survey data. Pain 1990;43(3):299-307.

[5]. Adorno M L, Brasil-Neto JP. Assessment of the quality of life through the SF-36 questionnaire in patients with chronic nonspecific low back pain. Acta Ortop Bras 2013;21(4):202-207.

[6]. Lehman, GI. Resistance training for performance and injury prevention in golf. J Can Chiropr Assoc 2006;50(1):27-42.

[7]. M cGill S. Low back disorders: evidence based prevention and rehabilitation. Champaign, IL: Human kinetics;2002.

[8]. Behm DG, Anderson KG. The role of instability with resistance training. J Strength Cond Res 2006;20(3):716-722.

[9]. Akuthota V, Nadler SF. Core strengthening. Arch Phys Med Rehabil 2004;85(1):86-92.

[10]. Kavcic N, Grenier S, M cGill SM. Quantifying tissue loads and spine stability while performing commonly prescribed low back stabilization exercises. Spine 2004;29(20):2319-2329.

[11]. Andrusaitis SF, Brech GC, Vitale GF, Greve JMDA. Trunk stabilization among women with chronic lower back pain: a randomized, controlled, and blinded pilot study. Clinics 2011;66(9):1645-1650.

[12]. Schilling JF, M urphy JC, BonneyJR, Thich JL. Effect of core strength and endurance training on performance in college students: randomized pilot study. J Bodyw M ov Ther. 2013;17(3):278-290.

[13]. BergmarkA. Stability of the lumbar spine. A study in mechanical engineering. Acta Orthop Scand Suppl 1989; 230:1-54.

[14]. Stanford M E. Effectiveness of specific lumbar stabilization exercises: A single case study. J M an M anip Ther 2002;10(1):40-46.

[15]. Whitaker J. Abdominal ultrasound imaging of pelvic floor muscle function in individuals with low back pain. J M an M anipulative Ther 2004;12(1):4449.

[16]. Faries M , Greenwood M . Core training: Stabilizing the confusion. Strength Cond J 2007;29(2):10-15.

[17]. Danneels LA, Vanderstraeten GG, Cambier DC, Witvrouw EE, Stevens VK, De Cuyper HJ. A functional subdivision of hip, abdominal, and back muscles during asymmetric lifting. Spine 2001;26(6):114121.

[18]. Liddle SD, Baxter GD, Gracey JH. Exercise and Chronic low back pain: what works? Pain 2004;107(1):176190.

[19]. Tettamanti A, Barbero M, Balestri A, Calori G. Efficacy of trunk balance exercises for individuals with chronic low back pain: a randomized clinical trial. J Orthop Sports Phys Ther 2011;41(8):542-552.

[20]. Standaert C], Herring SA. Expert opinion and controversies in musculoskeletal and sports medicine: core stabilization as a treatment for low back pain. Arch Phys Med Rehabil 2007;88(12):1734-1736.

[21]. May S, Johnson R. Stabilisation exercises for low back pain: a systematic review. Physiotherapy 2008;94(3):179-189.

[22]. Ferreira ML, Ferreira PH, Latimer J, Herbert RD, Hodges PW, Jennings M D, M aher CG, Refshauge KM. Comparison of general exercise, motor control exercise and spinal manipulative therapy for chronic low back pain: a randomized trial. Pain 2007;131(1):31-37.

[23]. França FR, Burke TN, Hanada ES, M arques AP. Segmental stabilization and muscular strengthening in chronic low back pain: a comparative study. Clinics 2010;65(10):1013-10177.

[24]. Aluko A, DeSouza L, Peacock J. The effect of core stability exercises on variations in acceleration of trunk movement, pain, and disability during an episode of acute nonspecific low back pain: a pilot clinical trial. J Manipulative Physiol Ther 2013;36(8):497-504.

[25]. Standaert C], Weinstein SM, Rumpeltes]. Evidenceinformed management of chronic low back pain with lumbar stabilization exercises. Spine 2008;8(1):114-120.

[26].Lienhard K, Lauermann SP, Schneider D, ItemGlatthorn JF, Casartelli NC, M affiuletti NA. Validity and reliability of isometric, isokinetic and isoinertial modalities for the assessment of quadriceps muscle strength in patients with total knee arthroplasty. J Electromyogr Kinesiol 2013;23(6):1283-1288.

[27]. Dvir Z, Keating J. Reproducibility and validity of a new test protocol for measuring isokinetic trunk extension strength. Clin Biomech 2001;16(7):627630.

[28]. Jerome J, Hunter K, Gordon P, M cKay N. A new robust index for measuring isokinetic trunk flexion and extension. Spine 1991;16(7):804-808.

[29]. Thorp L, Wimmer M, Foucher K, Sumner D, Shakoor $\mathrm{N}$, Block J. The biomechanical effects of focused muscle training on medial knee loads in OA of the knee: a pilot proof of concept study. J M usculoskelet Neuronal Interact 2010;10(2):166-173.

[30]. Yahia A, Ghroubi S, Kharrat O, Jribi S, Elleuch M, Elleuch $\mathrm{MH}$. A study of isokinetic trunk and knee muscle strength in patients with chronic sciatica. Ann Phys Rehabli M ed 2010;53(4):239-249.

[31]. M cGill SM , Childs A, Liebenson C. Endurance times for low back stabilization exercises: clinical targets for testing and training from a normal database. Arch Phys M ed Rehabil 1999;80(8):941-944. 
[32]. Okubo $Y$, Shiraki H. Effects of two types of trunk exercises on balance and athletic performance in youth soccer players. Int I Sports Phys Ther 2014;9(1):47-57.

[33]. Okada T, Huxel KC, Nesser TW. Relationship between core stability, functional movement, and performance. J Strength Cond Res 2011;25(1):252-261.

[34].Del Pozo-Cruz B, Mocholi MH, del Pozo-Cruz J, Parraca JA, Adsuar JC, Gusi N. Reliability and validity of lumbar and abdominal trunk muscle endurance tests in office workers with nonspecific subacute low back pain. J Back M usculoskelet Rehabil 2014;27(4):399-408.

[35]. Evans K, Refshauge KM, Adams R: Trunk muscle endurance tests: reliability, and gender differences in athletes. J Sci M ed Sport 2007;10(6):447-455.

[36]. M cGill S. Low back disorders: evidence-based prevention and rehabilitation. $2^{\text {nd }}$ edition. Champaign, IL: Human Kinetics; 2007.

[37]. M acDonald DA, M oseley GL, Hodges PW. The lumbar multifidus: does the evidence support clinical beliefs. Man Ther 2006;11(4):254-263.

[38]. Puntumetakul R, Areeudomwong P, Emasithi A, Yamauchi J. Effect of 10-week core stabilization exercise training and detraining on pain-related outcomes in patients with clinical lumbar instability. Patient Prefer Adherence 2013;7:11891199.

[39]. Tertti M O, Salminen JJ, Paajanen HE, Terho PH, Kormano MJ. Low-back pain and disk degeneration in children: a case-control M R imaging study. Radiology 1991;180(2):503-507.

[40]. Hides JA, Stokes MJ, Saide M, Jull GA, Cooper DH. Evidence of lumbar multifidus muscle wasting ipsilateral to symptoms in patients with acute/subacute low back pain. Spine 1994;19(2):165-172.

[41]. Stokes GM , M ilner AD, Upton C]. Is thoraco-abdominal phase relationship an indicator of sleep state? Eur J Pediatr 1992;151(7):526-527.

[42]. Parkkola R, Rytokoski U, Kormano M. M agnetic resonance imaging of the discs and trunk muscles in patients with chronic low back pain and healthy control subjects. Spine 1993;18(7):830-836.

[43]. Kader DF, Wardlaw D, Smith FW. Correlation between the MRI changes in the lumbar multifidus muscles and leg pain. Clin Radiol 2000;55(2):145149.

[44]. Rackwitz B, de BR, Limm H, von GK, Ewert T, Stucki G. Segmental stabilizing exercises and low back pain. What is the evidence? A systematic review of randomized controlled trials. Clin Rehabil 2006;20:55367.

[45]. Porterfield JA. Mechanical low back pain: perspectives in functional anatomy. $2^{\text {nd }}$ edition. Philadelphia: W.B. Saunders Company; 1998.
[46]. Richardson C, Jull G, Hodges P, Hides], Panjabi M M. Therapeutic exercise for spinal segmental stabilization in low back pain: scientific basis and clinical approach. New York, NY: Churchill Livingstone; 1999.

[47]. Arokoski JP, Valta T, Kankaanpaa M, Airaksinen, 0. Activation of lumbar paraspinal and abdominal muscles during therapeutic exercises in chronic low back pain patients. Arch Phys Med Rehabil 2004;85(5):823-832.

[48]. Rissanen A, Heliovaara M, Alaranta H, Taimela S, M alkia E, Knekt $P$, Reunanen A, Aromaa A. Does good trunk extensor performance protect against backrelated work disability? J Rehabil Med 2002;34(2):62-66.

[49]. M cGill S, Grenier S, Bluhm M, Preuss R, Brown S, Russell C. Previous history of LBP with work loss is related to lingering deficits in biomechanical, physiological, personal, psychosocial and motor control characteristics. Ergonomics 2003;46(7):731746.

[50].Moon HJ, Choi KH, Kim DH, Kim HJ, Cho YK, Lee $\mathrm{KH}$, Kim JH, Choi YJ. Effect of lumbar stabilization and dynamic lumbar strengthening exercises in patients with chronic low back pain. Ann Rehabil Med 2013;37(1):110-117.

[51]. Ebrahimi H, Blaouchi R, Eslami R, Shahrokhi M. Effect of 8-week core stabilization exercises on low back pain, abdominal and back muscle endurance in patients with chronic low back pain due to disc herniation. PTJ. 2014;4(1):25-32.

[52]. Yilmaz F, Yilmaz A, M erdol F, Parlar D, Sahin F, Kuran B. Efficacy of dynamic lumbar stabilization exercises in lumbar microdiscectomy. J Rehabil Med 2003;3(4):163-167.

[53]. Kumar C, Rao S, Thakur P. Effectiveness of core stability exercise program on abdominal and back strength in school going children: A randomized controlled trial. IJND 2015;5(7):7-13.

[54]. Abdallah A, Beltagi A. Effect of core stability exercises on trunk muscle balance in healthy adult individuals. IJM PS 2014;8(5):223-239.

[55]. M cGill SM. Distribution of tissue loads in the low back during a variety of daily and rehabilitation tasks. J Rehabil Res Dev 1997;34(4):448-458.

[56]. Akbari A, Khorashadizadeh S, Abdi G. The effect of motor control exercise versus general exercise on lumbar local stabilizing muscles thickness: randomized controlled trial of patients with chronic low back pain. J Back Musculoskeletal Rehabil 2008; 21(2):105-112.

[57]. Axler CT, M cGill SM . Low back loads over a variety of abdominal exercises: searching for the safest abdominal challenge. Med Sci Sports Exerc 1997;29(6):804-811.

How to cite this article: Sobhy M Aly. TRUNK MUSCLES' RESPONSE TO CORE STABILITY EXERCISES IN PATIENTS WITH CHRONIC LOW BACK PAIN: A RANDOMIZED CONTROLLED TRIAL. Int J Physiother Res 2017;5(1):1836-1845. DOI: 10.16965/ijpr.2016.201 